1. MBBS, FCPS

Senior Registrar Department of General Surgery DHQ Teaching Hospital, Sahiwal.

2. MBBS, FCPS

Associate Professor

Department of General Surgery

Sahiwal Medical College, Sahiwal.

3. MBBS, FCPS

Associate Professor

Department of General Surgery

Sahiwal Medical College, Sahiwal.

4. MBBS, MRCS, FCPS

Assistant Professor

Department of General Surgery

Sahiwal Medical College, Sahiwal.

5. MBBS, FCPS

Assistant Professor

Department of General Surgery

Sahiwal Medical College, Sahiwal.

6. MBBS, FCPS

Senior Registrar

Department of General Surgery

DHQ Teaching Hospital, Sahiwal.

Correspondence Address:

Dr. Waqas Hussain Qureshi

Care Hospital, Near Bhandari Chowk

Sahiwal.

waqashusain@hotmail.com

Article received on:

01/04/2018

Accepted for publication:

$31 / 08 / 2019$

\section{COMPARATIVE STUDY OF GLYCERYL TRINITRATE OINTMENT VERSUS LATERAL INTERNAL SPHINCTEROTOMY IN MANAGEMENT OF CHRONIC ANAL FISSURE.}

\begin{abstract}
Waqas Hussain Qureshi', Zahid Sattar ${ }^{2}$, Akhtar Mahboob ${ }^{3}$, Aakif Yousaf ${ }^{4}$, Sajid Mukhtar ${ }^{5}$, Waleeja Shamikha ${ }^{6}$

ABSTRACT... Objectives: To compare efficacy of topical $0.2 \%$ glyceryl trinitrate ointment with lateral internal sphincterotomy in treatment of patients with chronic anal fissure. Study Design: Randomized Control Trial. Setting: Department of General Surgery, DHQ Teaching Hospital, Sahiwal. Period: From 20 September 2016 to 31 December 2017. Material \& Methods: A total number of 60 patients included in this study and divided into two groups GTN and LIS group through computer generated randomization method. Three main outcome variables were assessed in this study; pain relief, healing of fissure and recurrence. SPSS version was used to analyze data. $P$ value $\leq 0.05$ was considered as significant. Results: A total number of 60 patients included in this study. Relief of pain GTN and LIS was (95\%) and (86.7\%) respectively. Fissure healing GTN and LIS was noted as (88.3\%) and (83.3\%) respectively. Recurrence was not found in any patient of the present study. Relief of pain was statistically significant. Conclusion: Topical application of GTN ointment for relief of pain is safe and effective method for relief of chronic anal fissure but pain relief is slow. On other hand lateral internal sphincterotomy is first line treatment and treatment of choice for chronic anal fissure when performed by an experienced surgeon.
\end{abstract}

Key words: $\quad$ Chronic Anal Fissure, Glyceryl Trinitrate, Lateral Internal Sphincterotomy, Pain Relief.

Article Citation: Qureshi WH, Sattar Z, Mahboob A, Yousaf A, Mukhtar S, Shamikha W. Comparative study of Glyceryl Trinitrate ointment versus lateral internal sphincterotomy in management of Chronic anal fissure. Professional Med J 2019; 26(12):2241-2245. DOI: 10.29309/TPMJ/2019.26.12.4330

\section{INTRODUCTION}

Term anal fissure rendered to the painful condition due to mucosal tear of distal anal canal extending below the dentate line and ends at anal verge..$^{1,2}$ Most common cause of anal fissure is trauma to anus of anal canal which affects normal bowel movements. Other causes include hard stool or recurrent episodes of diarrhea. ${ }^{3}$ Insertion of anima tip, rectal themameter and ultrasonic probe may cause anal trauma. Anal fissures diagnosed in all age groups but young healthy adults diagnosed most likely without gender difference. ${ }^{4}$

Common symptoms of anal fissures include pain, per rectal bleeding, constipation and mucosal discharge. ${ }^{5}$ Predominantly fissures found in midline among them 90 percent found posterior and 10 percent interiorly. ${ }^{6}$ A fissure more than 6 weeks old with indurated margins on digital rectal examination, exposure of horizontal fibers, and fibrosis at basis and sentinel tag labeled as chronic anal fissure. ${ }^{7}$

Fissure also associated with anal spasm and stenosis of internal anal sphincter which reduced the blood flow and delayed the healing process. ${ }^{8}$ In 1951 Eisenhammer introduced internal sphincterotomy and later on Parks described lateral open spenecterotomy in 1967 for the management of anal fissures. ${ }^{9}$ After sometime closed spinecterotomy was also described. In is also a useful agent for relaxation of internal sphincter muscles which allows fast healing by increase of blood supply of this region. ${ }^{10}$

We conducted this randomized control teial to compare effecacy of topical $0.2 \%$ glyceryl trinitrate (GTN) ointment vs lateral internal sphincterotomy (LIS) in the treatment chronic anal fissure and to fulfill the gap of research on this topic in our local 
area.

\section{METHODOLOGY}

This randomized control trial was conducted in the department of general surgery, DHQ Teaching Hospital, Sahiwal from 20 September 2016 to 31 December 2017. Study was started after ethical approval from hospital ethical board and informed consent from patients. Non probability consecutive sampling technique was used. Total number 60 patients were included in the study after calculations. Sample size was calculated from WHO sample size calculator. Adult patients of age 20 years to 40 years diagnosed as anal fissures of more than 6 weeks were included in the study. Patients taking any kind of medicine for illness like ischemic heart disease, any immunity deficiency (human immune deficiency virus), pregnant women, anal fissures of bowel disease, Crohn's disease ulcerative colitis and tuberculosis were excluded from the study. Patients were divided into two equal groups with computer generated randomization method, 30 patients in each group. Group GTN and group LIS, GTN group was treated with GTN $2 \%$ ointment for six weeks and LIS group treated surgically with lateral internal sphincterotomy method.

Pain was assessed with visual analogue scale score consist of 10 numbers 0 to 10 . Zero score means no pain and score 10 represents severe pain. After start of treatment patients were asked to intake fibers diet and followed up at every 2 weeks initially and then after $3^{\text {rd }}$ week till six weeks. At every visit patients were examined for fissure healing, pain relief and any type of complications. If fissure was healed patient asked to stop GTN application and continue fibrous diet. To see recurrence patients were followed up till 3 months after complete healing. In GTN group any patient who was not treated completely offered to avail LIS mode of treatment.

Collected data was entered in a computer software SPSS version 24 and analyzed for mean SD of numerical data like age and VAS score frequency percentages for categorical data like complete healing of anal fissures and recurrence rate. Chi square test was applied to see association of outcome variable. $P$ value $\leq 0.05$ was considered as significant.

\section{RESULTS}

A total number of $n=60$ patients were included in this study, both gender. Gender distribution revealed as $n=32$ (53.3\%) male and $n=28$ (46.7\%) females, (Figure-1). The mean age was $26.42 \pm 3.80$ years. Relief of pain GTN and LIS was $n=57(95 \%)$ and $n=52(86.7 \%)$ respectively. Fissure healing GTN and LIS was noted as $n=53(88.3 \%)$ and $n=50$ (83.3\%) respectively. No recurrence was found in the present study. Headache was reported in $n=20(33.3 \%)$ patients of GTN group and only $n=3(5 \%)$ reported in LIS group. Relief of pain $(p=0.002)$ and headache $(p=0.000)$ were statistically significant. (Table-I).

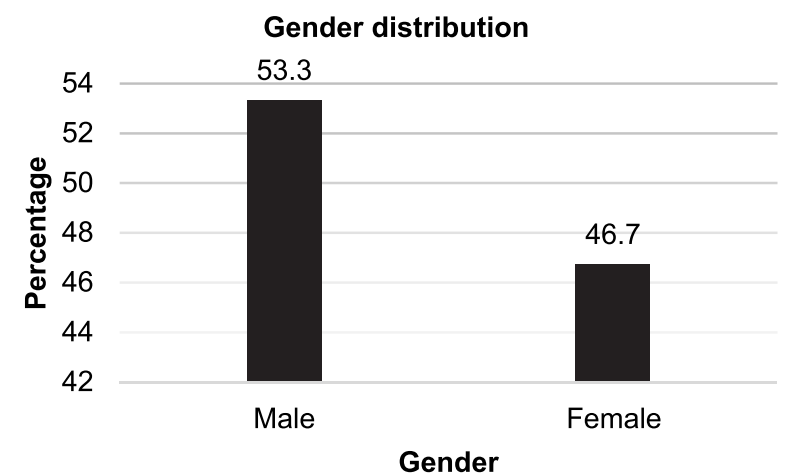

\begin{tabular}{|c|c|c|c|c|c|c|}
\hline Author & Year & No. & Duration & GTN & LIS & P-Value \\
\hline \multicolumn{7}{|l|}{ Relief of pain } \\
\hline Present study & 2018 & 60 & 6 weeks & (95\%) & $(86.7 \%)$ & $p=0.002$ \\
\hline \multicolumn{7}{|l|}{ Fissure healing } \\
\hline Present study & 2018 & 60 & 6 weeks & $(88.3 \%)$ & $(83.3 \%)$ & $p=0.321$ \\
\hline \multicolumn{7}{|l|}{ Recurrence } \\
\hline Present study & 2018 & 60 & 24 months & 0 & 0 & $p=0$ \\
\hline \multicolumn{7}{|c|}{ Complication, headache } \\
\hline Present study & 2018 & 60 & 24 months & $n=20(33.3 \%)$ & $n=3(5 \%)$ & $p=0.000$ \\
\hline \multicolumn{7}{|c|}{ Table-I. Comparison of outcome variables in both groups } \\
\hline Professional M & 12):2 2 & & www.th & fesional.com & & 2242 \\
\hline
\end{tabular}




\section{DISCUSSION}

Management of 6 weeks older anal fissures may include conservative and surgical interventions. GTN and LIS are two effective methods for the treatment of anal fissures in our study we compare both groups with respect pain relief, fissure healing and recurrence. Among these outcome variables LIS found to be more effective with respect to complete healing, for relief of symptoms and temporary relief GTN is effective. In a study conducted by Siddiqui et al ${ }^{11}$ reported that $84.85 \%$ of patients after internal sphincterotomy have complete healing and $35.84 \%$ of patients have complete healing after GTN ointment application. This shows supremacy of LIS group. $P$ values was $<0.001$ a significant value. Complete healing was assessed at six week of follow up duration.

In another study conducted by Mishra et $\mathrm{al}^{12}$ reported that after treatment of six week GTN application 18 patients out of 20 patients were healed and after LIS 17 out of 20 patients were healed. Which shows better outcome in GTN group as compare to LIS group? This study is also comparable with our study. Only side effect reported in this was headache $25 \%$ patients' complaint about mild headache in GTN group and 1 patient in LIS group was found with hematoma. A similar study was conducted by Bansal et $\mathrm{al}^{13}$ reported GTN is safe and effective mod of treatment and good alternative of all kinds of anal fissures treatment. But in case of GTN failure LIS can be used as treatment option. In this study $72 \%$ of patients treated with GTN healed fissures completely whereas in group LIS all patients $100 \%$ healed completely at six week of treatment.

In another study conducted by Leo et $\mathrm{al}^{14}$ complete healing 53.6\% in GTN group and $86.7 \%$ in LIS group with P value 0.004 a significant value. While in our study complete healing was $88.3 \%$ and $83.3 \%$ respectively and $P$ value was 0.321 also a non significant value. Study of Leo et $\mathrm{al}^{14}$ also comparable with our study. He reported relief of pain in $86.6 \%$ of patients and $96.6 \%$ of patients respectively. In our study relief of pain was $95 \%$ and $86.7 \%$ respectively.

Another study conducted by Muhammad et $\mathrm{al}^{15}$ reported relief of pain $56.66 \%$ and $96 \%$ in GTN and LIS group respectively whereas healing of complete fissures was reported $50 \%$ and $96 \%$ in GTN and LIS group respectively. This study is also comparable with our study with respect of all three outcome variables. Third variable that was observed in our study was recurrence.

Recurrence of anal fissures was not found in any patient of our study in both groups. A similar study was conducted by Oettle GJ et $\mathrm{al}^{16}$ and reported similar finding that recurrence was not observed in any patient in both GTN and LIS groups. This study is comparable with our study. Another study was conducted by Ellaban et $\mathrm{al}^{17}$ in 2010 and reported 2.5\% recurrence in GTN group and no recurrence were reported in LIS group. This study is also comparable with our study. Recurrence was not found in study conducted by Leo et $\mathrm{al}^{14}$ in 2011. In study of Bansal et $\mathrm{al}^{13}$ which was conducted in 2015 reported $11 \%$ recurrence in GTN group and 8\% in LIS group these findings also shows superiority of LIS.

Many authors who conducted studies on this topic reported similar findings about relief of pain, healing rate and recurrence rate and also reported that LIS is a treatment of choice when performed by some experienced and skilled surgeon. ${ }^{18,19,20}$

\section{CONCLUSION}

Topical application of GTN ointment for relief of pain is safe and effective method for relief of chronic anal fissure but pain relief is slow. On other hand lateral internal sphincterotomy is first line treatment and treatment of choice of chronic anal fissure when performed by an experienced surgeon.

Copyright@ 31 Aug, 2019.

\section{REFERENCES}

1. Mousavi SR, Sharifi M, Mehdikhah Z. A comparison between the results of fissurectomy and lateral internal sphincterotomy in the surgical management of chronic anal fissure. J Gastrointest Surg. 2009; (7):1279-82.

2. Vimal V, Senthilvel S. Comparative study of lateral sphincterotomy and local application of $2 \%$ diltiazem gel in treatment of chronic anal fissure. Int J Sci Stud 2017; 5(2):185-189. 
3. Gandomkar H, Zeinoddini A, Heidari R, Amoli HA. Partial lateral internal sphincterotomy versus combined botulinum toxin a injection and topical diltiazem in the treatment of chronic anal fissure: A randomized clinical trial. Dis Colon Rectum. 2015; 58(2):228-34.

4. Malik RB. Ahmad I. A comparative study of open vs close lateral sphincterotomy in the management of chronic anal fissure - A day case study. PJHMS. 2017; 11(1):403-05.

5. Ankur P, Chandra PP, Keshav A, Srivastava SM, Sharma AD. A comparative study of role of topical diltiazem $2 \%$ organo gel and lateral internal sphincterotomy for the management of chronic fissure in ano. International Journal of Contemporary Medical Research 2016; 3(5):1363-65.

6. Hang MTH, Smith BE, Keck C, Keshavarzian A, Sedghi $S$. Increasing efficacy and reducing side effects in treatment of chronic anal fissures: A study of topical diazepam therapy. Huang. L, ed. Medicine. 2017; 96(20):e6853.

7. Ravindranath Singh, Puneet Pal Singh Oberoi, Nisith Kumar Ray. "A study of evaluation of local infiltration of botulinum toxin as compared to lateral sphincterotomy in the management of chronic anal fissure." Journal of Evolution of Medical and Dental Sciences 2015; (4)95:16057-63.

8. Sanniyasi S, Alexander N, Thiyagarajan M. Open versus closed lateral internal sphincterotomy in chronic anal fissures: A prospective study. Int J Sci Stud 2016; 4(7):124-126.

9. Ebinger, S.M., Hardt, J., Warschkow, R. Operative and medical treatment of chronic anal fissures-a review and network meta-analysis of randomized controlled trials. J Gastroenterol. 2017; 52:p663.

10. Motie M, Hashemi P. Chronic anal fissure: A comparative study of medical treatment versus surgical sphincterotomy. Acta Medica Iranica 2016; 54(7):437-440.
11. Siddique MI, Murshed KM, Majid MA. Comparative study of lateral internal sphincterotomy versus local $0.2 \%$ glyceryl trinitrate ointment for the treatment of chronic anal fissure. Bangladesh Med Res Counc Bull 2008; 34:12-15.

12. Mishra R, Thomas S, Maan MS, Hadke NS. Topical nitroglycerin versus lateral internal sphincterotomy for chronic anal fissure: Prospective randomized trail. ANZ J Surg 2005; 75:1030-1031.

13. Bansal AR, Tripura R, Godara R, Jaikaran. Comparative study of glyceryl trinitrate ointment versus lateral internal sphincterotomy in management of chronic anal fissure. Arch Clin Gastroenterol 2016; 2(1):013016.

14. Leo FT, Shindhe VV, Aithala PS, Martis JJS, Shenoy HD. Comparative study of glyceryl trinitrate ointment versus surgical management of chronic anal fissure. Int J Surg 2005; 73:268-277.

15. Muhammad IA, Pervaiz A, Figueiredo R. Internal sphincterotomy versus topical nitroglycerin ointment for chronic anal fissure. Asian J Surg 2014; 37:15-19.

16. Oettle GJ. Glyceryl trinitrate vs. Sphincterotomy for treatment of chronic fissure-in-ano: A randomized, controlled trial. Dis Colon Rectum 1997; 40:13181320.

17. Ellabban GM, Elkazaz G, Hokam E. Local glyceryl trinitrate versus lateral internal sphincterotomy in management of anal fissure. World J Surg. 2010; 2:17.

18. Utzig MJ, Krosean AJ, Buhr HJ. Concepts in pathogenesis and treatment of chronic anal fissure-a review of literature. Am J Gastroenterol 2003; 8:968974.

19. Gibbons CP, Read NW. Anal hypertonia in fissures: Cause or effect. Br J Surg 1986; 73:443-45.

20. Corby H, Donnelly VS, O' Herlihy C, O Connel PR. Anal canal pressure are low in women with postpartum anal fissures. Br J Surg 1987; 84:86-88. 


\section{AUTHORSHIP AND CONTRIBUTION DECLARATION}

\begin{tabular}{|c|l|l|l|}
\hline Sr. \# & Author(s) Full Name & \multicolumn{1}{|c|}{ Contribution to the paper } \\
1 & $\begin{array}{l}\text { Waqas Hussain } \\
\text { Qureshi } \\
2\end{array}$ & $\begin{array}{l}\text { Conceived the idea and planned } \\
\text { the study, qcquisition of data. } \\
\text { Drafting and writing of the } \\
\text { manuscript, acquisition of data. } \\
\text { Drafting and writing of the } \\
\text { manuscript, acquisition of data. } \\
\text { Statistical analysis and } \\
\text { interpretation of data. } \\
\text { Revision of the manuscript \& } \\
\text { editing of manuscript. } \\
\text { Revision of the manuscript \& } \\
\text { editing of manuscript. }\end{array}$ \\
\hline 5 & Akhtar Mahboob & Aakif Yousaf & Sajid Mukhtar \\
\hline
\end{tabular}

